\title{
MOVIMIENTOS SOCIALES Y DEMOCRACIA: MODOS DE LO POLÍTICO
}

\author{
Social Movements and Democracy: Forms of the Political \\ Paola Gramaglia \\ Universidad Nacional de Córdoba \\ paolagramaglia@gmail.com
}

\begin{abstract}
Resumen:
En este trabajo sostendré la hipótesis que desde finales de los años noventa del siglo veinte en América Latina se ha producido un ciclo de movilizaciones sociales y políticas que interpelaron a las democracias neoliberales latinoamericanas (1997-2007). La emergencia de estas movilizaciones sociales y políticas representó el principal aporte para pensar de otro modo y relevar de nuestros archivos las formas clásicas europeas de la filosofía política que nos tuvieron apresados, en moldes categoriales insuficientes para comprender nuestros propios contextos. Tales como las dualidades de lo público/privado; sociedad civil/estado; sociedad civil/sociedad política; ciudadanía/democracia.
\end{abstract}

\section{Palabras clave:}

Movimientos sociales, sujetos políticos, heterogeneidad social, democracia.

\begin{abstract}
:
In this work, I will develop the hypothesis about how since the last years of 20th century in Latin America there has been many social and political movements that interpellated Latin-American neoliberal democracies (1997-2007). The emergency of this social and political movements represented the main contribution for us, intellectuals to be able start thinking in a different way and to get free from our own files about political philosophy which had classical European shapes that had us caught in insufficient categories to understand our own contexts. Such as the duality between public/private; society/state; civil society/political society; citizenship/democracy.
\end{abstract}

\section{Keywords:}

Social movements, Political subjects, Social heterogeneity, Democracy. 
La perspectiva que me parece pertinente es la que se abre mirando lo económico/político desde lo social; es decir, organizar los pensamientos sobre la transformación desde la clave que abre el par social/económico-político.

Raquel Gutiérrez (2015).

A partir de las dictaduras de los 70s, en oleadas sucesivas y con diversas estrategias, se fue instalando en América latina el neoliberalismo como dinámica social predominante en el proceso de producción y reproducción de la vida social.

En el marco de estas irrupciones neoliberales, surgieron a lo largo de Nuestra América diversas formas de lucha, organización y subjetivación políticas que intentan construir horizontes sociales emancipatorios.

En una rápida caracterización de estos emergentes políticos podemos decir que existe un conjunto de experiencias vinculadas a narrativas nacional-populares de vocación más bien estatalistas; y otras, vinculadas a narrativas popular-comunitarias, más proclives a formas de acción política de cuño autonomista. Se han intentado dar cuenta de la diversidad política de estas experiencias en las discusiones y debates sobre hegemonía y eticidad en Laclau-Mouffe (1987) y en Dussel (2001); sobre estatalismos y abigarramiento en García Linera (2010) y Tapia (2010) o sobre gubernamentalidades y autonomías en Gago (2014) y Gutiérrez Aguilar (2015); por nombrar algunos.

La opción entre estas grandes narrativas políticas se presenta muchas veces, tanto en la arena política como en el campo de discusión teórica de un modo maniqueo que conlleva una pérdida de visión sobre matices, complejidades e hibridaciones teóricas de significación política. Generalmente sus interpretadores las presentan como antagónicas, como si tuviéramos que debatirnos entre las potencialidades estatalistas y autonomistas.

En cambio, en este trabajo pretendo analizar la emergencia de las movilizaciones sociales y políticas que señalaron la distancia entre lo social y su representación política con el fin de valorarlas como el principal aporte para pensar de otro modo lo político en relación a la democracia. Al mismo tiempo que relevar de nuestros archivos las formas clásicas europeas de la filosofía política que nos tuvieron apresados en moldes categoriales insuficientes para comprender nuestros propios contextos. Tales como las dualidades de lo público/privado; sociedad civil/estado; sociedad civil/sociedad política; ciudadanía/democracia.

\section{HETEROGENEIDAD SOCIAL}

Desde finales de los años noventa del siglo veinte en América Latina se ha producido un ciclo de movilizaciones sociales y políticas que interpelaron a las democracias neoliberales latinoamericanas $(1997-2007)^{1}$. Las mismas interpelaron no sólo a las

${ }^{1}$ Esta hipótesis ha sido sostenida por distintos grupos de intelectuales tales como: Proyecto colonialidad/modernidad; Grupo de estudios subalternos latinoamericanos; Centro latino- 
prácticas políticas liberales sino que también erosionaron las teorías y categorías que representaban cierta legitimidad de ese tipo de democracia restringida. Señalando lo exiguas de sus proposiciones y la distancia que se hacía cada vez más evidente entre las prácticas sociales y políticas y, las teorías de esos procesos sociales locales.

En este convulsionado periodo se dieron debates, discusiones y reapropiaciones conceptuales de intelectuales e investigadores de las ciencias sociales y de las humanidades que acompañaron estos procesos sociales de diverso tipo. Re-orientaron sus categorías y sus indagaciones encarnando la producción de conocimiento desde los mismos mundos heterogéneos latinoamericanos.

El quiebre de paradigmas y el agotamiento de los mapas cognitivos produjeron una ineficacia del relato eurocentrista moderno para poder explicar y comprender nuestros propios mundos latinoamericanos. Se debe sumar la propia crisis del conocimiento moderno producido en Europa que desconfiaba de sus propias nociones clásicas de verdad, razón, identidad, objetividad y universalidad. Es decir: una crisis del objeto, del sujeto y del conocimiento mismo de lo latinoamericano que focaliza dichos contextos en la producción de las ciencias sociales y de las humanidades proyectadas hacia un conocimiento autónomo.

Para esclarecer cual es mi posición teórica dentro del campo de la filosofía política es que considero pertinente hacer una genealogía precaria, pero necesaria de los planteos y autores tratados en ese periodo en las academias universitarias. A finales de los años ochenta y comienzo de los noventa del siglo veinte, mientras las dictaduras perdían su fuerza, la sociedad civil conseguía articularse y organizarse sobre las ideas reguladoras de democracia y de ciudadanía. En el ámbito académico latinoamericano, más específicamente en el campo de la filosofía política, se tratan estos nuevos procesos democráticos con las herramientas y conceptos del canon de la academia occidental europea.

Una tendencia en estas perspectivas en el tratamiento de lo filosófico político es la idea de que la modernidad representa el modelo universal. La propuesta de Habermasiana, asume cierto consenso en nuestras academias como el lugar de la modernidad no acabada. Una tendencia diferente, más bien desencantada de las revoluciones y de la democracia que surge luego de la caída del muro de Berlín, comienza a reflexionar y a pensar más seriamente la relación con las prácticas políticas concretas para desarrollar fundamentos filosóficos que la hagan más cercana

americano de Ciencias sociales CLASCSO; la sociología crítica latinoamericana; la teoría social latinoamericana; et al. Un par de ejemplos sólo para considerar como el momento de quiebre de este ciclo de movimientos sociales a políticos. El 6 de setiembre de 1997 el Ejército Zapatista de Liberación Nacional, emerge en el escenario político. Demanda el cumplimiento de los acuerdos de San Andrés y en contra de la militarización de las zonas indígenas, marchará a la ciudad de México con 1.111 miembros del EZLN que representan a los 1.111 pueblos zapatistas. Esta gran marcha zapatista e indígena llegará al DF el 12 de septiembre de este año. El cierre del ciclo lo representan los casos de incumplimiento de los gobiernos progresistas con sus mandatos constitucionales y sus acuerdos políticos con los movimientos sociales que los acompañaron. Tal es el caso de la extracción minera en Yasuní-ITT Ishipingo-TambocochaTiputini la selva ecuatoriana en 2007 y el caso del Territorio Indígena y Parque Nacional Isiboro Secureen la Amazonía boliviana TIPNIS en 2011. 
a las necesidades de las mayorías democráticas. Uno de los autores que en ese momento leíamos en la primavera de la democracia en Argentina, era Norberto Bobbio. Las indagaciones que nos proponía el autor estaban pensadas claramente no desde una perspectiva liberal sino más bien de desconfianza de las mismas. La pregunta por las posibilidades de la democracia y el mercado era una de las preocupaciones centrales (aún no se pensaba en el neoliberalismo y si se lo entendía era una extensión del viejo liberalismo).

Las inquietudes de Norberto Bobbio en su texto El futuro de la democracia son más que claras al respecto y se pregunta: "¿Qué cosa es la democracia sino un conjunto de reglas (las Ilamadas reglas de juego) para solucionar los conflictos sin derramamiento de sangre? ¿En qué cosa consiste el buen gobierno democrático, si no, y sobre todo, en el respeto riguroso de estas reglas?" (1986:136) ${ }^{2}$.

La otra tendencia, más claramente liberal y que en los años noventa del siglo veinte fue muy trabajado en las academias universitarias de la región y de difusión en los ámbitos de investigación, es la propuesta de John Rawls (1979: 135) ${ }^{3}$. Una teoría filosófica aparentemente desideologizada, pero que invisibiliza su propia cesión de parte en favor de lo dado como tal, y se afana en los mejores procedimientos para una sociedad de derecho. Prioriza la voluntad del sujeto (en abstracto: libre e igual) con tipos de garantías o proposición de principios éticos de libre convención. La idea de que lo político se define en relación al bien, no por sí mismo, sino en relación a lo normativo, es claramente, el modelo de la modernidad anclada en lo jurídico. Tanto las versiones garantistas que se dan a partir de la modernidad a las distintas formas de convivencia social, como las convenciones o consensos que se han propuesto para organizar el vivir colectivo, propiciaron establecer valores universales que se convierten en prioritarios y excluyentes para la legitimidad de esas conformaciones sociales ${ }^{4}$.

A raíz de este tipo de argumentos, la racionalidad de lo universal para las distintas tendencias señaladas precisa necesariamente de la homogeneidad social y cultural que legitima la prescripción del accionar colectivo. Estas perspectivas se asientan, insisto, en la legitimidad de una universalidad homogénea, propia de las sociedades europeas de ese periodo ${ }^{5}$, refuerzan la idea de que depende del grado de integración de esa universalidad de valores, la legitimidad de lo político.

\footnotetext{
${ }^{2}$ El subrayado es mío.

${ }^{3}$ El análisis de los temas tratados en las secciones de Filosofía Política y Ética en los Congresos de la Asociación Filosófica de la República Argentina (AFRA) en el periodo de 1990 hasta 2001. Informes de la Investigación del que participé como integrante en el Proyecto de investigación aprobado por Secretaría de Ciencia y Tecnología de la Universidad Nacional de Córdoba SECYT (2003).

${ }^{4}$ El subrayado es mío.

${ }^{5}$ En la actualidad autores como Sandro Mezzadra tratan la problemática de la identidad cultural ante las inmigraciones de los últimos años y la emergencia de la diversidad de culturas y valores en Europa. Véase Sandro Mezzadra (2005) Derecho de fuga. Migraciones, ciudadanía y globalización. Madrid: Traficantes de sueños.
} 
La emergencia de los nuevos movimientos sociales y políticos hace evidente la heterogeneidad social y reclama nuevas categorías epistémicas de análisis. A propósito Chantal Mouffe (1999:205) plantea la relevancia del pluralismo de valores, atendiendo a las heterogeneidades sociales, cuestión que en América se ha leído como una deficiencia: "Esta debe ser considerada como una empresa 'ético-política' (interesada en los valores específicos que pueden ser realizados en el reino de la política mediante la acción colectiva que no desconoce el rol constitutivo del conflicto y del antagonismo, ni el hecho de que la división sea irreductible). Este último punto indica por qué el 'pluralismo de valores' en sus múltiples dimensiones debe ser tomado en serio por lo filósofos políticos."

En esta dirección es clara la perspectiva que plantea Quijano a partir de considerar la heterogeneidad histórica estructural de América latina la cual podría ser pensada como una clave de nuestra ontología de lo social.

Aníbal Quijano sostiene que debiéramos tener más presente que lo público como lo privado son concepciones relativamente recientes en la historia, y que la escisión entre ambos ámbitos tuvo su origen en justificar la aparición del Estado por contraposición a la actuación de la sociedad civil. Cuando que en realidad ambas dimensiones representan simplemente aspectos de un mismo fenómeno en los que se enmarcan dimensiones del sujeto, que nos permiten una comprensión de los procesos políticos locales latinoamericanos íntimamente vinculados con los mundos sociales en los que se producen.

En sus investigaciones señala que en Europa, la modernidad se consolida de una cierta forma como parte de la experiencia cotidiana, al mismo tiempo como práctica social y como su ideología legitimadora. En América Latina por el contrario, y hasta bien entrado el siglo veinte, se instala una profunda y prolongada brecha entre la ideología de la modernidad y las prácticas sociales, no infrecuentemente dentro de las mismas instituciones sociales o políticas. En particular, la modernidad es una forma ideológica legitimadora de prácticas políticas que van claramente en contra de su discurso, mientras las prácticas sociales modernas son reprimidas porque no pueden ser legitimadas por ninguna instancia de las ideologías dominantes (Quijano, 2014: 710).

En América Latina la contracara de esa modernidad se da en la colonialidad del poder que introduce una particular forma de organización, clasificación y legitimación del orden social, política y económica que configura otros modos.

La colonialidad es uno de los elementos constitutivos y específicos del patrón mundial de poder capitalista. Se funda en la imposición de una clasificación racial/étnica de la población del mundo como piedra angular de dicho patrón de poder y opera en cada uno de los planos, ámbitos y dimensiones, materiales y subjetivas, de la existencia social cotidiana y a escala societal. Se origina y mundializa a partir de América. Con la constitución de América (Latina), en el mismo momento y en el mismo movimiento histórico, el emergente poder capitalista se hace mundial, sus centros hegemónicos se localizan en las zonas situadas sobre el Atlántico que después se identificarán como Europa- y como ejes centrales de su nuevo patrón de dominación se establecen también la colonialidad y la 
modernidad. En breve, con América (Latina) el capitalismo se hace mundial, eurocentrado y la colonialidad y la modernidad se instalan asociadas como los ejes constitutivos de su específico patrón de poder, hasta hoy (Quijano, 2011: 237).

\section{DEMOCRACIA E IGUALDAD POLÍTICA}

Desde este lugar teórico que presento, valoro y defino a la democracia en relación con formas de construcción de lo social porque considero que crea, recrea e instituye modos de relaciones sociales y políticas que configuran formas sociales y societales ${ }^{6}$ adecuadas para pensar la heterogeneidad histórica de nuestras sociedades.

Carlés afirma que ni la tradición republicana ni la tradición liberal pueden explicar por sí misma justamente ese aspecto central de la ciudadanía que es la comunalidad, la membresía de un cuerpo de iguales, que no es lo mismo que una homogeneidad social. La igualdad es política.

Paradójicamente, es en la tercera gran tradición del pensamiento político occidental, en la tradición democrática, donde encontramos los elementos que nos permiten comprender la siempre precaria fijación de un límite comunitario, esto es, la posibilidad misma de una membresía (Carlés: 2009:45)

Atada a las instituciones tradicionales de la democracia representativa, la reducida política neoliberal viene acompañada de una visión también restringida, minimalista de la democracia. Lo mismo ocurre con la capacidad de administración de los recursos del Estado. Ambos (democracia y estado) deben ser limitados al mínimo indispensable. Esa contracción es selectiva y sus consecuencias son la profundización de la exclusión exactamente de aquellos sujetos, temas y procesos que pueden amenazar el avance del proyecto neoliberal en América latina hasta bien entrados los años noventa del siglo veinte (podría agregar a toda la semiperiferia y periferia) (Amin, 2009: 7). Esta forma posdictadura de democracia restringida mereció y sigue mereciendo un intenso debate en el cual sea posible desde distintas tradiciones de pensamiento, debatir los sentidos y sus alcances, sobre todo, en un período en que las acciones más cuestionables ética y políticamente, se realizan en nombre de ella y en contra de ella: la democracia.

Ahora bien, como resistencia a estas gestiones democráticas ceñidas a lo normativo, a lo estrictamente procedimental pero básicamente, a excluir a las grandes mayorías de las decisiones como a las minorías no representadas en una ciudadanía inclusiva, una vez más, -en distintas regiones de América Latina- se produjeron

\footnotetext{
6 "El carácter multisocietal está dado por el hecho de que los sistemas de relaciones sociales existentes en el país corresponden a diferentes tipos de civilización, la una agraria y la otra moderna capitalista, a las que corresponden diferentes modos de transformación de la naturaleza en los procesos de producción y diferentes formas de organización del gobierno de las mismas" Tapia, Luis (2002). La condición multisocietal. Multiculturalidad, pluralismo, modernidad. Muela del diablo-CIDES. Bolivia, p. 16.
} 
resistencias. Las mismas se produjeron entre estos sectores excedentes y los Estados democráticos restringidos, es decir, se produce la emergencia del subsuelo político.

El subsuelo es parte de la complejidad producida por el movimiento de las sociedades, pero que no es reconocida ni asumida. El exceso produce una complejidad no funcional. Entre los intersticios de las esferas separadas de la vida moderna y por fuera y debajo de las instituciones oficiales, la vida se hace invisible. La visibilidad política y social se da a través de las instituciones del capital y del estado, así como también a través de un conjunto de instituciones de la sociedad civil. La producción del orden moderno también ocurre como una composición de instituciones políticas y sociales en torno a una nueva arquitectura de las separaciones (Tapia, 2008:37).

Es a partir de este subsuelo que se fueron dando cambios cualitativos en las relaciones entre el Estado y lo social, como así también emergen distintos tipos de sociedades al interior de las mismas sociedades modernas que configuran formas societales a partir de la emergencia de comunidades que preexisten en nuestra región. Sobre todo en algunas regiones de la América andina y central (países tales como Bolivia y Ecuador) tales procesos implicaron e intervinieron en una transformación del Estado no eurocentrado.

En este contexto y durante ese particular periodo, se pensó a la democracia como crítica al modelo mínimo de representación. Cada vez más se asoció con formas de construcción de lo social, creando y recreando nuevos modos de sociedad que instituyen otros modos de lo político. Es en este sentido que puede definírsela a la democracia desde este lugar teórico como un modo sustancial de ser de lo social (Laclau, 1980:31).

En algunas regiones de la América andina y central (países tales como Bolivia y Ecuador) tales procesos sociales plantearon una transformación fundamental del Estado, ya no, en una versión moderna-europea ilustrada que precisaba de un momento revolucionario para la toma del poder del Estado. Más bien, rediscutieron la naturaleza del estado en sus propios contextos de sociedades multisocietales. En otras regiones como Chiapas en México, por ejemplo, se abandona como forma política al Estado para discutir y rediseñar formas de auto-gobierno.

A partir de estas experiencias antisistémicas, América Latina se convierte en un observatorio social. Los intelectuales latinoamericanos que poseían la matriz teórica de las disciplinas de la modernidad europea, enfocan su atención a los cambios sociales del continente y es a partir de estos que reorganizan sus mapas cognitivos.

\section{ESTRATEGIAS DE CONSTITUCIÓN DE SUJETOS POLÍTICOS}

Teniendo en cuenta estas consideraciones propongo ahora sí, el análisis de cuatro tipos de estrategias experimentadas en este periodo mencionado como formas políticas de lo social teniendo presente la perspectiva de Laclau en su dinámica de las formas de construcción de hegemonía y diferencias. Estrategias, en tanto que los movimientos sociales a partir de determinadas coordenadas históricas y contingentes, dirigen una serie de acciones para constituir un modo político propio. 
La primera de ellas es la que denomino de constitución nacional-popular. Los movimientos sociales a partir de su fuerza de organización y de movilizaciones callejeras amplían la esfera democrática, construyendo una hegemonía, conjuntamente con partidos políticos, para la toma del poder estatal. De esta manera, el Estado se constituye como momento teleológico final. Esto es posible a través de una doble lógica de articulación, por un lado, la que Laclau denomina lógica de la diferencia y por otro, la lógica de la equivalencia, para articular el momento hegemónico (Gramaglia, 2008: 74).

Es particularmente visible si focalizamos el proceso como un desarrollo lineal y progresivo. En el gobierno de la "revolución democrática y cultural" de Evo Morales en Bolivia al ganar democráticamente las elecciones con el $54 \%$ de los votos, frente al 28\% de su rival Jorge Quiroga (conservador), permitió por primera vez en la historia de Bolivia (país que tiene la mayor población indígena de América del Sur) que un indígena llegue al poder y se apreste a dirigir un país que hasta entonces sólo había sido conducido por generaciones de "blancos". Esta hegemonía y toma de poder del Estado, permitió concebir el momento político por excelencia: la reforma de la "Constitución plurinacional" ${ }^{7}$ en 2009, la cual implicó cambios fundamentales en relación a la juridicidad moderna.

En su artículo 30. I. Es nación y pueblo indígena originario campesino toda la colectividad humana que comparta identidad cultural, idioma, tradición histórica, instituciones, territorialidad y cosmovisión, cuya existencia es anterior a la invasión colonial española.

II. En el marco de la unidad del Estado y de acuerdo con esta Constitución las naciones y pueblos indígena originario campesinos gozan de los siguientes derechos:

1. A existir libremente.

2. A su identidad cultural, creencia religiosa, espiritualidades, prácticas y costumbres, y a su propia cosmovisión.

3. A que la identidad cultural de cada uno de sus miembros, si así lo desea, se inscriba junto a la ciudadanía boliviana en su cédula de identidad, pasaporte u otros documentos de identificación con validez legal.

4. A la libre determinación y territorialidad.

5. A que sus instituciones sean parte de la estructura general del Estado.

6. A la titulación colectiva de tierras y territorios.

7. A la protección de sus lugares sagrados.

8. A crear y administrar sistemas, medios y redes de comunicación propios.

\footnotetext{
${ }^{7}$ Recordemos que las estrategias de resistencia (para este período) en Bolivia comenzaron con la guerra del agua. La guerra del Agua es el nombre popular de una serie de protestas que tuvieron lugar en Cochabamba, la tercera ciudad más poblada de Bolivia, entre los meses de enero y abril de 2000. Su detonante fue la privatización del abastecimiento de agua potable municipal.
} 
9. A que sus saberes y conocimientos tradicionales, su medicina tradicional, sus idiomas, sus rituales y sus símbolos y vestimentas sean valorados, respetados y promocionados.

10. A vivir en un medio ambiente sano, con manejo y aprovechamiento adecuado de los ecosistemas.

11. A la propiedad intelectual colectiva de sus saberes, ciencias y conocimientos, así como a su valoración, uso, promoción y desarrollo.

12. A una educación intracultural, intercultural y plurilingüe en todo el sistema educativo.

13. Al sistema de salud universal y gratuito que respete su cosmovisión y prácticas tradicionales.

14. Al ejercicio de sus sistemas políticos, jurídicos y económicos acorde a su cosmovisión.

15. A ser consultados mediante procedimientos apropiados, y en particular a través de sus instituciones, cada vez que se prevean medidas legislativas o administrativas susceptibles de afectarles. En este marco, se respetará y garantizará el derecho a la consulta previa obligatoria, realizada por el Estado, de buena fe y concertada, respecto a la explotación de los recursos naturales no renovables en el territorio que habitan.

16. A la participación en los beneficios de la explotación de los recursos naturales en sus territorios.

17. A la gestión territorial indígena autónoma, y al uso y aprovechamiento exclusivo de los recursos naturales renovables existentes en su territorio sin perjuicio de los derechos legítimamente adquiridos por terceros.

18. A la participación en los órganos e instituciones del Estado.

III. El Estado garantiza, respeta y protege los derechos de las naciones y pueblos indígena originario campesinos consagrados en esta Constitución y la ley.

En esta dirección deberíamos considerar el proceso también dado por los movimientos sociales locales a través de la Constitución de la República del Ecuador de 2008, durante el gobierno de Rafael Correa. En la misma se modifica en modo sustancial la relación del hombre con la naturaleza al garantizar en su Carta Magna el derecho a la naturaleza. En el capítulo séptimo dice:

Art. 71.- La naturaleza o Pacha Mama, donde se reproduce y realiza la vida, tiene derecho a que se respete integralmente su existencia y el mantenimiento y regeneración de sus ciclos vitales, estructura, funciones y procesos evolutivos. Toda persona, comunidad, pueblo o nacionalidad podrá exigir a la autoridad pública el cumplimiento de los derechos de la naturaleza. Para aplicar e interpretar estos derechos se observarán los principios establecidos en la Constitución, en lo que proceda. El Estado incentivará a las personas naturales y jurídicas, y a los colectivos, para que protejan la naturaleza, y promoverá el respeto a todos los elementos que 
forman un ecosistema ${ }^{8}$. Así mismo se establece que el Estado garantizará la restauración de la Naturaleza, además de aquellas restricciones o medidas de precaución encaminadas a evitar que se altere el ecosistema.

La segunda de las estrategias, la denominé guevarista, en tanto responde a la idea política desarrollada por el Che Guevara, quien sostenía que para combatir al capitalismo era necesario provocar múltiples Vietnam. Puede comprenderse desde una lógica de las diferencias que tiene la capacidad de articular con otras diferencias, pero sin vocación de construir un proceso hegemónico. La misma se replica en proliferaciones de la misma demanda, consiguiendo producir un efecto de interpelaciones múltiples y ampliadas, sin aspirar al momento teleológico final en la toma del poder del Estado. Un ejemplo de ello es la interpelación por una reforma agraria para los campesinos sin tierra por lo que milita el Movimiento de los trabajadores rurales sin tierra en Brasil (MST) ${ }^{9}$. Esta forma puede definirse atravesada tanto, por articulaciones contingentes de lo social y lo político.

La tercera es la que denomino pos-nacional-popular. La lógica de la diferencia es la más radicalizada, ya que se instituyen a sí mismos a través de la constitución de autonomía política, en modalidades de agenciamiento de la mujer indígena en formas políticas asamblearias-comunitarias. Se distancian de cualquier articulación que implique una nueva forma Estado. No necesitan para su propia configuración política comunitaria de una articulación equivalente de demandas, ni del momento teleológico final en la toma del poder del Estado; como es el caso del Movimiento Zapatista de Liberación nacional $(E Z L N)^{10}$. Y puede considerarse que las organizaciones de las naciones mapuches marchan por ese camino, así como las comunidades de las tierras bajas en Bolivia y Ecuador.

A modo de análisis de lo hasta acá expuesto, tanto el caso de los movimientos sociales de Bolivia como el del MST y el Zapatismo, encarnan tres modalidades diferentes en las que se ha producido un desplazamiento cualitativo, en los procesos que se instituyeron desde movimientos sociales a movimientos políticos. Han producido un cambio desde los modos individuales de ciudadanía moderna liberal a modos colectivos de lo político propio de éstas experiencias latinoamericanas.

\footnotetext{
${ }^{8}$ Constitución de la República del Ecuador, consultado el 25 de abril de 2016, disponible en: http://www.asambleanacional.gov.ec/documentos/constitucion_de_bolsillo.pdf.

${ }^{9}$ Recordemos que en Brasil el MST junto con el PT fueron aliados para este nuevo periodo de gobierno, Se originó en la oposición al modelo de reforma agraria impuesto por el régimen militar, principalmente en los años 1970, que priorizaba la colonización de tierras en regiones remotas, con los objetivos de exportar los excedentes poblacionales y de la integración estratégica. Contrariamente a este modelo, el MST busca fundamentalmente la redistribución de las tierras improductivas. El grupo se encuentra entre los movimientos sociales más grandes de Latinoamérica contando entre sus miembros a un millón y medio de campesinos sin tierra organizados a lo largo de 23 de los 27 estados de Brasil.

${ }^{10}$ Recordemos que el MZLN interpeló a la sociedad mundial con una novísima forma de comunicación y el comienzo de las marchas al centro de la Metrópoli de la ciudad de México con reivindicaciones por los derechos indígenas.
} 
Al mismo tiempo, han promovido experiencias de gobierno de democracia ampliada, que sobrepasan la versión moderna restringida de las políticas neoliberales, con intervenciones políticas por fuera de la representación partidaria y, con modos de auto-organización y auto-gobiernos asamblearios.

Así también, el derecho a la propiedad de la tierra tanto, en la apropiación rural como en la urbana, aparecen fuertemente como demandas en las tres estrategias que junto con la interpelación a la juridicidad política interpelan específicamente a la naturaleza misma del fundamento de los estados modernos, instituidos en dos principios claves: la propiedad privada y la individualidad ciudadana.

La cuarta de las estrategias, que defino como complementaria a las recién descriptas, refiere a las políticas que patrocinaron algunos gobiernos populares en los primeros momentos de gobierno en las últimas décadas en la región. (ArgentinaVenezuela). Habría que tener cuidado de la diferencia en la forma de politización y reorganización que estos gobiernos ponen en marcha, pues se efectúa en un sentido inverso al practicado por los movimientos sociales a políticos recién descriptos, que venían en procesos sociales de construcciones "desde abajo". En este otro caso, se explican desde procesos sociales desde la gobernanza. Es decir, los Estados nacionales determinan y definen gestionar lo popular y de esta manera reinscriben las acciones estatales políticas a través de un empoderamiento en derechos para las minorías y acciones estatales que favorecen a las mayorías. Estas acciones se llevaron a cabo a través de una red de programas estatales, para distintos estamentos y diferentes tipos sociales y culturales de la población (colectivo de mujeres, colectivo LGTB, jóvenes estudiantes et al). Para algunos mereció el tratamiento del concepto de "Autonomía relativa del Estado" (Vilas, 2008) ${ }^{11}$ en la medida que el Estado y la Nación se colocan por encima de los intereses privados y la cuestión social se asume como política de Estado ${ }^{12}$. En una forma aún estatal que trama modos de lo político, imbricando fenómenos de nuevos tipos de relaciones entre lo político y la democracia, modifican formas de subjetivación y de ciudadanía. Me refiero a las experiencias de los gobiernos populares o populistas del chavismo en Venezuela y del kirchnerismo en Argentina.

\section{PeNSAR ESCENARIOS EMANCIPADORES}

Pensar las configuraciones políticas del presente implica atender también a los conceptos que se ponen en juego en este tipo de interpretaciones y re-significaciones. En ellos los pasados coloniales se cuelan insistentemente en las interrupciones e

\footnotetext{
${ }^{11}$ Una de las articulaciones relevantes entre movimientos sociales y líderes gubernamentales fue en la coincidencia de una mayoría de países latinoamericanos que hicieron una gran apuesta antiimperialista, anti-neoliberal y latinoamericanista, y uno de esos momentos fue en 2005, con la cumbre en Mar del Plata donde se le dijo No al Área de Libre Comercio de las Américas (Alca) . Las nuevas propuestas de integración prometen cambios transversales para la región dependiendo de la coyuntura política de las democracias populares.
}

${ }^{12}$ El subrayado es mío. 
intervenciones del flujo histórico de los procesos sociales y políticos de igualdad en la región.

Ahora bien, re-pensando las cuatro estrategias mencionadas, es claro, que los gobiernos nacional populares de estos procesos históricos que tienen como común denominador precisamente, concebir los procesos necesarios de una ampliación de ciudadanía en los términos de la igualdad política, y al mismo tiempo una distribución más equitativa de las riquezas, parecieran no ser efectivos para romper con la hegemonía de las élites y modificar la matriz neoliberal del capitalismo globalizado en esta parte sur del mundo.

Quizás, debiéramos insistir con lo que plantea Raquel Gutiérrez cuando dice que es necesario partir del punto de vista social, que es precisamente desde dónde hemos estado analizando las transformaciones políticas en América Latina en este trabajo. Para lo cual nuestro problema se invierte: "El problema central de la construcción de una estructura de gobierno, reflexionando desde el ámbito de la reproducción material de la vida social, es la contención de la monopolización de la riqueza material y de la decisión política" (Gutiérrez, 2015:141).

Tratando de concluir, pero sin cerrar el tema, es necesario atender los límites políticos, económicos y ecológicos de las políticas progresistas nacionales populares de este particular periodo. Ya que, a pesar del enorme esfuerzo en el reconocimiento y la revalorización de las identidades comunitarias indígenas, así como en la ampliación de derechos y con ello en un cambio en la calidad de ciudadanía, la no modificación de la matriz capitalista neoliberal en su versión extractivista neodesarrollista, aparece como un límite que tiene implicancias no sólo en las relaciones intersubjetivas, sino en las relaciones del hombre con la naturaleza y con todos los seres vivos, en los que la habitan y a quienes beneficia (Svampa,2016:382)

Re-pensar el sujeto político a partir de los mismos procesos de lucha, implica un trabajo de crítica y de reformulación de categorías de conocimiento. Esto requiere al mismo tiempo que situarlas en el conflicto de las intervenciones de los mismos sujetos de las heterogeneidades, ponerlas en juego en los entramados de los saberes como una contribución en las disputas por el registro historiográfico que tiene como nervio las indagaciones de una filosofía política que nos interesa tener como matriz teórica.

Las experiencias populares de movilización social y reivindicación sociocultural en nuestros días han transformado las circunstancias políticas para una reconstrucción del conocimiento social latinoamericano, asumiendo su conflictividad y heterogeneidad. Desde este lugar, me planteo la necesidad de continuar acompañando las luchas sociales con reformulaciones críticas del conocimiento en Nuestra América desde una Filosofía Política latinoamericana, no sólo como proyecto teórico, sino como parte integrante de un proceso político efectivamente existente de transformaciones profundas, y para ello es necesario retomar legados y aceptar los límites de las políticas pensadas hasta ahora para construir escenarios emancipadores. 


\section{BIBLIOGRAFÍA}

Amin, Samir (2009). Introducción. Franz Fanon en África y Asia. En Fanon, F. Piel Negra, máscaras blancas. Madrid: Akal.

Bobbio, Norberto (1986). El futuro de la democracia. México: Fondo de Cultura Económica.

Carlés, Gerardo Aboy (2009). La sangre de Esteno. Transformaciones de la ciudadanía en la Argentina: del populismo a la inflexión particularista. En G. Dálmata (coord.) Movilizaciones sociales ¿nuevas ciudadanías? Buenos Aires: Biblos.

Dussel, Enrique (2001). Hacia una filosofía política crítica. Bilbao: Descleé.

Gago, Verónica (2014). La razón neoliberal. Economías barrocas y pragmática popular. Buenos Aires: Tinta Limón.

García Linera, Álvaro (2010). El Estado en transición. Bloque de poder y punto de bifurcación. En AAVV. El Estado como campo de lucha. La Paz: Muela del diabloCLACSO.

Gramaglia, Paola (2008). La democracia radicalizada en Ernesto Laclau. Serie Estudios Sociales y Políticos. Facultad de Filosofía. Universidad Nacional de Córdoba. Córdoba-Jorge Sarmiento Editor-Universitas Libros.

Gutiérrez Aguilar, R (2015). Horizonte comunitario-popular. Antagonismo y producción de lo común en América Latina. Cochabamba: SOCEEAutodeterminación.

Labastida Martín del Campo, Julio (Comp.). (1980). Hegemonía y alternativas políticas en América Latina. México. Siglo XXI.

Laclau, Ernesto y Chantal Mouffe (1987). Hegemonía y estrategia socialista. Hacia una radicalización de la democracia. Madrid: Siglo XXI.

Mouffe, Chantal (1999). El Retorno de lo político. Barcelona: Paidós.

Olvera, Alberto, Evelina Dagnino y Aldo Panfichi (2003). La disputa por la construcción. Democrática en América Latina. México: Centro de Investigaciones y Estudios Superiores en Antropología Social (CIESAS).

Quijano, Aníbal (2011). Colonialidad del poder, eurocentrismo y América latina. En La colonialidad del saber: eurocentrismo y ciencias sociales. Perspectivas latinoamericanas. Caracas: UNESCO-CLACSO.

Quijano, Aníbal (2014). Lo público y lo privado. Un enfoque Latinoamericano. Cuestiones y horizontes: de la dependencia histórico-estructural a la colonialidad/descolonialidad del poder. Buenos Aires: CLACSO.

Svampa, Maristella (2016). Debates latinoamericanos. Indianismo, desarrollo, dependencia y populismo. Barcelona: Edhasa.

Tapia, Luis (2008). Política salvaje. La Paz: Muela del diablo-CLACSO.

Tapia, Luis (2009). Movimientos sociales movimientos societales. Cuadernos de Pensamiento Crítico Latinoamericano. Número 17 (2-3), 1-8. 
Tapia, Luis (2010). El Estado en condiciones de abigarramiento. En AAVV. El Estado como campo de lucha. La Paz: Muela del diablo-CLACSO.

Vilas, Carlos (2008). La revalorización del Estado después del "Consenso de Washington". ¿Hacia atrás o hacia adelante?. En Carolina Galindo, Ana María Sallenave, Adolfo Chaparro (Eds.) Estado, democracia y populismo en América Latina. Rosario: Universidad de Rosario-CLACSO. 